\title{
A INTERVENÇÃO PEDAGÓGICA NO JOGO DE PAPÉIS NO CONTEXTO EDUCACIONAL DA CRIANÇA PRÉ-ESCOLAR
}

\author{
Silvio Sena, Célia Maria Guimarães \\ Universidade Estadual Paulista - FCT/UNESP. Pós - Graduação em Educação, Presidente Prudente, SP. e-mail: \\ silvioseduc@presidenteprudente.sp.gov.br
}

\begin{abstract}
RESUMO
A presente comunicação deriva da pesquisa de Doutorado intitulada "A dialética entre a intervenção pedagógica no jogo de papéis e o desenvolvimento da criança pré-escolar", por meio da qual, se objetiva explicar a dialética implícita entre a adequada intervenção pedagógica no jogo de papéis e sua implicação para o processo de humanização da criança pré-escolar. O referencial teórico consubstancia-se de autores atrelados à Psicologia Histórico-Cultural. Elege como sujeitos, vinte crianças de uma turma de pré II de uma escola da rede municipal de ensino de Presidente Prudente. A metodologia, de natureza quali-quantitativa, se caracteriza como pesquisaintervenção. Os instrumentos para a coleta de dados se apresentam em registros cursivos, fotografias e filmagens. Como resultado, ambiciona-se a obtenção de avanços teóricos e metodológicos no que tange à questão do como intervir no jogo de papéis de forma a considerar e valorizar a intima relação entre esse fenômeno e o desenvolvimento da criança pré-escolar.

Palavras-chave: Jogo de Papéis, Criança Pré-Escolar, Psicologia Histórico-Cultural, Intervenção Pedagógica, Processo de Humanização.
\end{abstract}

\section{THE ROLE PLAY PEDAGOGICAL INTERVENTION IN PRE SCHOOL CHILDREN EDUCACIONAL CONTEXT}

\begin{abstract}
This communication comes from a PhD research entitled "The dialectic between the pedagogical intervention in the role play and the preschool child development", which it aims to explain the implicit dialectic between appropriate pedagogical intervention in the role play and its implication for the preschool child humanization process. The theoretical framework is embodied from authors linked to the Historical-Cultural Psychology. It chooses as subjects twenty preschool children from a public school in Presidente Prudente. The qualitative and quantitative nature methodology is characterized as research intervention. The instruments for data collection are presented in cursive records, photographs and records. As a result, it is sought to obtain theoretical and methodological advances to the question oh how to intervein in the role play in order to consider and value the close relationship between this phenomenon and the preschool child development.
\end{abstract}

Keywords: Role Play, Preschool Child, Historic-Cultural Psycology, Pedagogical Intervention, Humanization Process. 


\section{INTRODUÇÃO}

Sabe-se que, entre os educadores da Educação Infantil, há a generalização da ideia de que apenas depois de ter-se enriquecido a experiência individual da criança será possível desenvolver a sua capacidade para a prática do jogo de papéis em parceria. Todavia, defendemos a tese de que ambos os objetivos podem se complementar e contribuir de maneira mais efetiva na aquisição, por parte da criança, de um patamar mais evoluído de desenvolvimento e, como consequência, de uma prática educativa adequada, de formas positivas de conduta social.

Focada na concepção de que, sob a influência do adulto que, intencionalmente ou não, mostra à criança os modos de conduta socialmente estabelecidos, esta pesquisa objetiva, por um oportuno processo de intervenção no jogo de papéis, possibilitar, de forma gradual, o avanço do jogo individual ao jogo desenvolvido em parceria, de sorte a relacioná-lo com a integralidade do desenvolvimento da criança pré-escolar. Para tanto, pretendemos nos debruçar no jogo enquanto atividade, concebendo-o como resultado das conquistas alcançadas pela criança, nas distintas esferas de seu processo de humanização.

Sob o Enfoque Histórico-Cultural, conclui-se que o jogo tem um caráter social, em sua origem, natureza e conteúdo: "A base do jogo é social devido precisamente a que também o são sua natureza e sua origem, ou seja, a que o jogo nasce das condições de vida da criança em sociedade" (ELKONIN, 1998, p.36). Sabe-se, ainda, que a personalidade é o resultado de um processo iniciado com o nascimento da criança e se estende ao longo de toda a sua vida. Nessa perspectiva, para que possamos vir a entender as forças motivadoras do desenvolvimento infantil, precisamos tomar conhecimento do que determina o caráter psicológico da personalidade humana, em qualquer estágio de seu desenvolvimento. Por isso, o primeiro ponto se consubstancia no fato de que, "[...] durante o desenvolvimento da criança, sob a influência das circunstâncias concretas de sua vida, o lugar que ela objetivamente ocupa no sistema das relações humanas se altera" (LEONTIEV, 2012, p.59).

O autor aponta que, para estudarmos o desenvolvimento da psique infantil, devemos começar pela análise do desenvolvimento da atividade da criança. Somente com esse estudo é que se torna possível elucidar o papel das condições externas e internas de sua vida. Para ele, apenas assim poderemos compreender de maneira adequada o papel condutor da educação e da criação, de maneira a operar precisamente na atividade e atitudes diante 
da realidade, a fim de determinar a psique e a consciência da criança. O que desencadeia a transição de um estágio de desenvolvimento para o subsequente é justamente a mudança do tipo principal de atividade na relação dominante da criança com a realidade, na qual ela assimila a herança social e estabelece relações com seus semelhantes.

Nesse momento de sua vida, a brincadeira (jogo de papéis) se revela como a atividade principal, “[...] cujo desenvolvimento governa as mudanças mais importantes nos processos psíquicos e nos traços psicológicos da personalidade da criança, [...]" (LEONTIEV, 2012, p.65). Segundo o autor, da atividade principal

[...] dependem, de forma íntima, as principais mudanças na personalidade infantil, observadas em um certo período de desenvolvimento. É precisamente no brinquedo que a criança, no período pré-escolar, por exemplo, assimila as funções sociais das pessoas e os padrões apropriados de comportamento ("O que é um soldado do exército vermelho?", "O que fazem em uma fábrica o diretor, o engenheiro e o operário"?), e este é um momento muito importante de modelagem de sua personalidade. (LEONTIEV, 2012, p. 64-65).
Nesse panorama, o mundo que rodeia a criança se resume em dois grupos: um deles, constituído por pessoas inteiramente relacionadas a ela, afinidades estas que determinam suas conexões com todo o resto do mundo; e um segundo grupo, mais amplo, formado por todas as demais pessoas. Vale dizer que as relações da criança com o segundo grupo são mediadas pelas relações que ela estabelece, no primeiro grupo, mais íntimo. Todavia, a professora pré-escolar ocupa uma posição de destaque, nessa etapa da vida da criança. "Pode-se dizer que as relações com a professora fazem parte do pequeno e íntimo círculo dos contatos da criança" (LEONTIEV, 2012, p.60).

De acordo com essa proposta, concebemos formas particulares de participação do professor, embora sempre sob o critério da intencionalidade, perseguindo-se os seguintes objetivos: 10 Intervir e mensurar, a partir das premissas que constituem o jogo de papéis (caráter das ações, utilização de objetos substitutos, adoção de um papel e relação com coetâneos), o nível de jogo praticado pela criança; 2ㅇ - Estabelecer, de maneira dialética e integrada, a correlação entre o avanço do nível de jogo praticado pela criança e os elementos que medeiam, conformam e estruturam o processo de humanização (desenvolvimento) da criança pré-escolar, na perspectiva do Enfoque Histórico Cultural, a 
saber: o biológico, o social, o histórico, o cultural e a atividade.

\section{METODOLOGIA}

Por meio de procedimentos qualiquantitativos, esta investigação se efetiva com crianças pré-escolares a partir das implicações da intervenção pedagógica no jogo de papéis e do respectivo progresso, ou não, do nível observado do jogo de papéis. Caracteriza-se como pesquisaintervenção, na qual a relação pesquisador/objeto pesquisado é dinâmica e determinará os próprios caminhos da pesquisa, sendo uma produção do grupo envolvido (AGUIAR; ROCHA, 1997).

No que concerne à faixa etária e nível escolar, participam vinte crianças de uma turma do Pré II da Educação Infantil (quatro anos) da UE selecionada para o desenvolvimento da investigação.

Sob a base dos pressupostos do Enfoque Histórico Cultural, elege-se o nível de atuação da criança e a sua evolução, no jogo de papéis, como objeto central de análise, ou seja, como variável dependente ${ }^{1}$. Com a observação participante ${ }^{2}$, outorga-se à

\footnotetext{
${ }^{1}$ Para Kerlinger (1980) e Richardson (1985), a variável dependente pode ser definida como aquela afetada ou explicada pela variável independente, que, por sua vez, se consubstancia naquela variável que afeta outra variável, chamada variável dependente.

2 "O requisito básico de toda observação participante [...], reside na necessidade de que o cientista social ganhe a confiança das pessoas que estão sendo estudadas - de maneira que sua presença não rompa o curso natural dos acontecimentos, ou nele interfira de algum modo - de forma que proporcionem respostas sinceras às suas perguntas, e não escondam, de sua vista, atividades importantes" (BLALOCK, 1973, p.50-51).
}

intervenção pedagógica, no jogo de papéis, o status de principal recurso pedagógico; em outras palavras, a intervenção pedagógica como variável independente.

A coleta de dados se dá por meio de registros escritos, fotografias e filmagens. A permissão para utilização das imagens incididas das crianças procede do Parecer Consubstanciado do Comitê de Ética em Pesquisa (CEP) de 09/05/2014, no 644.590, emitido pela Universidade Estadual Paulista FCT/UNESP, Campus de Presidente Prudente. Convém enfatizar que tais recursos se postam como meios para que seja possível a retomada contextual e interpretativa das situações advindas do brincar (jogo de papéis) da criança pré-escolar.

A análise dos dados se efetiva com o cuidado em assegurar coerência entre o método e a posição teórica adotada. Valemonos da ideia de William Corsaro, de forma a alternar a observação empírica com a observação interpretativa obtida pela inserção de observação participante, de registros cursivos e imagens (fotografias e filmagens) em contextos holísticos (ADES, 2009).

A implementação total do trabalho empírico está prevista para um interstício de seis meses, com duas sessões semanais, cada qual de 01h00min. A pesquisa se molda nas seguintes fases: sondagem de constatação diagnóstica inicial, sucede nas quatro 
primeiras semanas; intervenção, principia a partir da quinta semana do trabalho empírico; e sondagem de constatação diagnóstica conclusiva, permeia as últimas três semanas do trabalho empírico e adota, por principal finalidade, a constatação em caráter conclusivo do avanço qualitativo, ou não, das crianças em relação ao jogo de papéis e aos respectivos processos de humanização (desenvolvimento).

\section{RESULTADOS}

Cada sessão de intervenção, por ser composta por assembleia prévia, contribui para que todos os protagonistas possam, pelo compartilhamento das experiências pessoais e pontos de vista, combinar os possíveis temas e papéis a serem acolhidos no jogo de papéis. Nessa perspectiva, os temas são eleitos e as experiências subjetivas relativas aos personagens genéricos, envoltos em cada trama, são argumentadas, debatidas e demonstradas, na intenção de se possibilitar 0 enriquecimento das representações individuais. Dessa feita, mesmo ainda se encontrando em fase inicial, a pesquisa já aponta resultados significativos ligados ao avanço no nível de jogo praticado em parceria.

Das sessões implementadas, cite-se o exemplo contido nas de número 3 e 4 , mais bem ilustrado no tópico subsequente, no qual, no brincar de príncipe/princesa, a aluna
"VP", ao incorporar uma princesa, em um primeiro momento se negou a aceitar como seu príncipe o aluno "L", que é negro, e, posteriormente, após o compartilhamento das experiências pessoais e pontos de vista respaldados em elementos da realidade objetiva, atinentes a cada personagem genérico abarcado nessa trama, veio a aceitálo.

\section{DISCUSSÃO}

A sessão no 3 (três) teve início com os cumprimentos e relato das experiências pessoais vivenciadas pelas crianças, no interstício entre a segunda e a terceira sessão de trabalho. Em subsequência, houve o compartilhamento das experiências pessoais e pontos de vista com à objetivação de enriquecer as representações individuais e, por consequência, as possibilidades do jogo de papéis; as crianças foram questionadas sobre as ações respectivas de personagens centrais e complementares para se estruturar as possíveis tramas, ao se abordar a multiplicidade de temas gerados na peculiaridade daquela sessão.

Dirigindo-nos especificamente ao jogo de papéis, dentre os temas acercados, o que gerou a possibilidade de intervir em uma rica situação, na qual estavam envolvidas qualidades morais, se identificou no brincar de príncipe e princesa. Muitas meninas disputavam os três vestidos de princesa 
disponíveis, enquanto os meninos, as espadas de plástico. A aluna "VP", desde o início da sessão, queria muito um vestido de princesa. A aluna " $A$ ", que estava de posse de um dos vestidos, disse a "VP" que, após brincar um pouco, the concederia a oportunidade de brincar com o traje. Após muito brincar, ela o entregou à "VP", que se dispôs a brincar.

Junto à professora regular, o professor pesquisador destacou ocorrências dessa natureza, até então muito comuns naquele contexto, isto é, os conflitos gerados pelas disputas entre as crianças por um mesmo brinquedo. Em seguida, exemplificou e reiterou verbalmente, às crianças, as possibilidades de negociação que elas poderiam vir a praticar, em relação ao bemvindo revezamento no uso dos brinquedos. Das falas proferidas com vistas a indicar a solução das situações de conflito e provocar a concatenação de ações e complementaridade de papéis, destaca-se a seguinte: "[...] se duas crianças quiserem brincar, por exemplo, com o mesmo carrinho de boneca, uma poderá fazer o papel de mamãe e a outra a de babá, titia, vovó, vovô, ou mesmo papai!".

Dando sequência ao relato da situação-cerne daquela sessão, "VP" disse à professora regular que precisava de um príncipe para brincar com ela; nesse momento, o aluno "L", que é negro, empunhava uma das espadas e dizia ser o príncipe. Imediatamente, a professora regular o sugeriu à princesa ("VP"), para que viesse a ser o seu príncipe. Porém, "VP" não o aceitou, retrucando que iria à procura de outra criança para representar esse papel. Não satisfeita, a professora regular, sem êxito, insistiu com a referida aluna para que viesse a aceitá-lo na brincadeira, como seu príncipe. Ao dialogarem sobre o incidente, os professores concluíram que a razão da atitude aparentemente discriminatória de "VP" resultaria dos modelos de príncipe e princesa existentes nas fábulas infantis, os quais geram e reafirmam a crença de que necessariamente um príncipe tem que se enquadrar no estereótipo culturalmente impregnado no senso comum, ou seja, que tem que ser belo, corajoso, branco etc. Entretanto, tendo em vista que, se o assunto em pauta viesse a ser discutido em assembleia, naquele momento, poderia vir a expor e constranger a criança ("VP"), os professores optaram por tratar melhor dessa questão, na aula que estava por vir.

$$
\text { A sessão subsequente ( } n \text { ㅇ 4) foi }
$$
iniciada como planejada, isto é, com o relato das experiências pessoais e retomada dos temas trabalhados nas sessões precedentes. Até aquele momento, as crianças revezavam o uso de objetos, sem instaurar uma dinâmica de complementaridade no brincar. Nesse sentido e visando a resgatar a situação 
emergida na aula anterior, o professor pesquisador inferiu falas direcionadas ao brincar de príncipe e princesa. Explicou e exemplificou que, se várias crianças quiserem brincar de príncipe e/ou princesa, essa tensão poderia ser resolvida com a adoção de papéis complementares; para tanto, fez uso da seguinte fala: "[...] para se brincar de príncipe e princesa se faz necessário também haver o rei, a rainha, a/o serviçal que arruma a princesa, o príncipe, e um ponto muito importante, sem súditos não há reinado!".

Ao centralizarem ações na objetivação do resgate da situação emergida na sessão anterior, os professores direcionaram os seguintes questionamentos: como é uma princesa? Como é um príncipe? As crianças responderam que a princesa é bonita, magra e loira. Por sua vez, o príncipe é cavalheiro, bonito e tem cabelos pretos. A partir dessas falas, de forma direta, a professora regular se dirigiu ao cerne da questão, perguntando: "Qual a cor da pele do príncipe?" As crianças prontamente responderam: "É igual à nossa, branca!". Imediatamente, a professora regular levantou-se e se aproximou do professor pesquisador, que tem pele parda, colocou seu braço ao lado do braço dele, e perguntou: "Nossas peles têm a mesma cor?" Após tal questionamento, houve uma pequena pausa e um silêncio absoluto. 0 professor pesquisador brincou, representando chorar, dizendo: "Ahhh, eu não posso ser príncipe!". Nesse ponto, as crianças se manifestaram eufóricas, afirmando que a professora regular e o professor pesquisador poderiam, sim, vir a ser príncipe e princesa. A professora regular comentou com o professor pesquisador que, em sua opinião, o aceite ocorreu em razão do vínculo afetivo estabelecido entre os professores e as crianças.

Dando continuidade à descrição da referida sessão, o professor pesquisador salientou que há príncipes e princesas de vários tipos físicos (brancos, pardos, orientais, negros etc.) e, apesar de naquela sessão ter-se discutido o brincar de príncipe, as crianças poderiam brincar da brincadeira que melhor Ihes conviesse. Durante o brincar espontâneo (de livre escolha), o ponto de maior destaque revelou-se no momento em que a professora regular chamou a atenção do professor pesquisador para uma trama que se desvelava, em um dos cantos da sala. A aluna "VP", que na sessão anterior havia rejeitado o aluno "L" como seu príncipe, naquele momento brincava como princesa bailando com seu príncipe, isto é, com o aluno em questão.

\section{CONCLUSÕES}

No exemplo em destaque, além dos avanços percebidos nas ações características direcionadas a cada papel assumido, na utilização de objetos substitutos e na 
complementaridade entre os papéis sociais assumidos no brincar infantil, denota-se a influência que exerce a adequada intervenção pedagógica no jogo de papéis.

A partir de informações e exemplos advindos das estórias infantis, dos filmes, fábulas, entre outros, as representações que "VP" tinha do tema derivavam de conceitos espontâneos, adquiridos por ela fora de contextos nos quais a instrução ocorre. Desse apêndice, por meio da palavra enquanto artefato cultural, os professores ampliaram, aprofundaram e sistematizaram as representações as quais ela e as demais crianças até então tinham sobre a matéria. Tal fato possibilitou a ampliação e o aprofundamento dos conceitos envolvidos, que, por terem sido tratados e articulados pelos professores no contexto educacional, se revelam como científicos (VYGOTSKY apud DANIELS, 2011). Enfim, a experiência vivenciada possibilitou a percepção da ampliação do entendimento e compreensão do tema, na perspectiva do mundo objetivo, a todos os sujeitos envolvidos.

\section{REFERÊNCIAS}

ADES, C. Um adulto atípico na cultura das crianças. In: MÜLER, F.; CARVALHO, A. M. A. (Org.). Teoria e prática na pesquisa com crianças: diálogos com William Corsaro. São Paulo: Cortez, 2009.

AGUIAR, K. F.; ROCHA, M. L. Práticas universitárias e a formação sóciopolítica. Anuário do Laboratório de
Subjetividade e Política, v.3, n. 4, p. 87-102, 1997.

BLALOCK, H. M. Introdução à pesquisa social. Rio de Janeiro: Zahar, 1973.

DANIELS, H. Vygotsky e a pesquisa. São Paulo: Loyola, 2011.

ELKONIN, D. B. Psicologia do jogo. São Paulo: Martins Fontes, 1998.

KERLINGER, F. N. Metodologia da pesquisa em ciências sociais: um tratamento conceitual. São Paulo: Editora Pedagógica e Universitária, 1980.

LEONTIEV, A. N. Uma contribuição à teoria do desenvolvimento da psique infantil. In: VYGOTSKY, L. S.; ALEXANDER, R. L.; LEONTIEV, A. N. Linguagem, desenvolvimento e aprendizagem. São Paulo: Ícone, 2012.

RICHARDSON, C. Pesquisa social. São Paulo: Atlas, 1985.

Recebido para publicação em 30/07/2014

Revisado em 25/08/2014

Aceito em 15/09/2014 